\title{
Leaders
}

\section{Lipoprotein (a) and stroke}

\author{
Haralampos J Milionis, Anthony F Winder, Dimitri P Mikhailidis
}

\begin{abstract}
Strokes are one of the most common causes of mortality and long term severe disability. There is evidence that lipoprotein (a) $(\operatorname{Lp}(a))$ is a predictor of many forms of vascular disease, including premature coronary artery disease. Several studies have also evaluated the association between $L p(a)$ and ischaemic (thrombotic) stroke. Several cross sectional (and a few prospective) studies provide contradictory findings regarding $\mathrm{Lp}(\mathrm{a})$ as a predictor of ischaemic stroke. Several factors might contribute to the existing confusion-for example, small sample sizes, different ethnic groups, the influence of oestrogens in women participating in the studies, plasma storage before $\operatorname{Lp}(a)$ determination, statistical errors, and selection bias. This review focuses on the $L p(a)$ related mechanisms that might contribute to the pathogenesis of ischaemic stroke. The association between $L p(a)$ and other cardiovascular risk factors is discussed. Therapeutic interventions that can lower the circulating concentrations of $L p(a)$ and thus possibly reduce the risk of stroke are also considered.

(F Clin Pathol 2000;53:487-496)
\end{abstract}

Keywords: atherothrombosis; fibrinogen; homocysteine; lipids; lipoprotein a; stroke

Strokes (cerebrovascular accidents) are considered to be one of the most common causes of mortality and long term severe disability. ${ }^{1}$ It is well documented that hyperlipidaemia is a powerful risk factor for ischaemic heart disease (IHD).$^{2-4}$ However, it was not until recently that the important role of lipids in the prevention of strokes was identified. ${ }^{5}$ There is a positive correlation between serum total cholesterol (TC) concentrations and ischaemic (thrombotic) stroke, and very low TC concentrations have been associated with an increased risk of haemorrhagic stroke. Raised low density lipoprotein cholesterol (LDL) or triglyceride (TG) concentrations, reduced high density lipoprotein cholesterol (HDL) concentrations, and a high TC to HDL ratio are associated with an increased risk of non-haemorrhagic stroke. ${ }^{5}$ There is evidence that lipoprotein (a) $(\mathrm{Lp}(\mathrm{a}))$ is a predictor of many forms of vascular disease, including premature coronary artery disease. ${ }^{6}$ Studies in subjects with average lipid profiles indicate that raised serum $\mathrm{Lp}(\mathrm{a})$ concentrations are associated with myocardial infarction, coronary stenosis, re-occlusion of aortocoronary bypass vein grafts, peripheral atherosclerosis, and cerebral ischaemia..$^{6-8}$

In this review, we focus on the possible role of $\mathrm{Lp}(\mathrm{a})$ in the pathogenesis of ischaemic (thrombotic) stroke. We scanned the National Library of Medicine (USA) search service in MEDLINE and Pre-MEDLINE (with links to participating online journals) and other related databases. Our research covered all languages and the years between 1962 and October 1999. The keywords were stroke, cerebrovascular accident, and $\mathrm{Lp}(\mathrm{a})$.

Lp(a): a link between atherogenesis and fibrinolysis

THE STRUCTURE OF Lp(a)

$\mathrm{Lp}(\mathrm{a})$ is an LDL like molecule consisting of an apoprotein (apo) B-100 particle attached by a disulphide bridge to apo(a). ${ }^{6} \mathrm{Apo}(\mathrm{a})$ is a member of a family of "kringle" containing proteins, such as plasminogen, tissue platelet activator (tPA), prothrombin, factor XII, and macrophage stimulating factor (MSF)..$^{10} \mathrm{Lp}(\mathrm{a})$ shares a high degree of sequence identity with plasminogen..$^{911}$

The apo(a) gene is highly polymorphic; more than 34 different sized alleles have been identified. ${ }^{12}$ Corresponding isoforms with molecular weights ranging from 187 to $648 \mathrm{kDa}$ were identified in human serum. ${ }^{13}{ }^{14}$ The size polymorphism of apo(a) is mainly the result of the genetically determined number of kringle IV type 2 repeats. ${ }^{12}$

MODULATION OF PLASMA Lp(a) CONCENTRATIONS Plasma $\mathrm{Lp}$ (a) concentrations are variable and their distribution in the general population is highly skewed (approximately $90 \%$ of the population has serum values less than $300 \mathrm{mg} /$ litre); occasional patients have values above $20000 \mathrm{mg} /$ litre. ${ }^{15} \mathrm{Lp}(\mathrm{a})$ exhibits a high degree of heritability through kringle isoform transmission. ${ }^{16}$ Nevertheless, certain metabolic abnormalities, as well as pharmacological agents, can influence the circulating concentrations of $\mathrm{Lp}(\mathrm{a})$. These values can be increased as part of the acute phase response, ${ }^{17}$ and in diabetes mellitus, ${ }^{18}$ chronic renal failure, ${ }^{19-21}$ nephrotic syndrome, ${ }^{22}{ }^{23}$ cancer $^{24}$ menopause, and hypothyroidism. ${ }^{25}$ The potential rise in circulating $\mathrm{Lp}(\mathrm{a})$ concentrations as part of the 
acute phase response is of special interest because the atherosclerotic process is thought to have an inflammatory component. ${ }^{26}$ Therefore, serum $\mathrm{Lp}$ (a) concentrations could perhaps be influenced by the presence of extensive vascular disease. $\mathrm{Lp}$ (a) values are decreased in liver failure ${ }^{27}$ and hyperthyroidism. ${ }^{28}$ Furthermore, nicotinic acid, ${ }^{29}$ tamoxifen, ${ }^{30}$ oestrogens, ${ }^{31}$ progesterone, and anabolic steroids $^{32}$ might decrease $\mathrm{Lp}$ (a) concentrations. Fibrates have been shown, in some studies, to reduce $\mathrm{Lp}$ (a) concentrations, ${ }^{33}{ }^{34}$ whereas statins might increase $\mathrm{Lp}(\mathrm{a})$ concentrations. ${ }^{35-37}$

APO(a) GENE POLYMORPHISM AND PHENOTYPES Plasma Lp(a) concentrations are inversely correlated with the size of the apo(a) isoform..$^{38}$ For example, significantly raised Lp(a) concentrations in patients with rheumatoid arthritis were caused mainly by an increase in the S3 (low molecular weight) isoform. ${ }^{39}$ However, recent evidence suggests that the contribution of the apo(a) isoform size to the control of plasma $\mathrm{Lp}(\mathrm{a})$ concentrations is considerably lower than previously thought. This is because the variability in plasma $\mathrm{Lp}(\mathrm{a})$ concentration is not uniform across the apo(a) size spectrum. ${ }^{16}{ }^{40}$ It is still unclear whether further apo(a) gene polymorphism (not affecting the size of the $\operatorname{Lp}(\mathrm{a})$ molecule) influences the circulating concentrations of $\operatorname{Lp}(a){ }^{41}$ Small (low molecular weight) isoforms are usually associated with higher total $\operatorname{Lp}(\mathrm{a})$ values (probably because assembly is less complex and thus faster) and a higher risk of atherogenesis compared with the large (high molecular weight) isoforms. ${ }^{42}$ It is also worth considering that the risk attributed to $\mathrm{Lp}(\mathrm{a})$ might not be continuous. Thus, very high concentrations might be substantially more dangerous than values closer to the epidemiological cut off value of $300 \mathrm{mg} /$ litre. $^{26}$ Whether the risk of stroke associated with a moderate increase of $\mathrm{Lp}(\mathrm{a})$ is conditioned by the coexisting LDL concentrations remains to be established.

THE PATHOPHYSIOLOGICAL LINK BETWEEN Lp(a) AND ATHEROTHROMBOSIS

The accumulation of $\mathrm{Lp}$ (a) molecules has been demonstrated in the arterial walls of human coronary and cerebral vessels. ${ }^{43}$ This process might be attributed to the tendency of apo(a) to bind to connective tissue elements, such as proteoglycans, glycosaminoglycans, and, especially, fibronectin. ${ }^{44}$ This binding process is promoted by lipoprotein lipase or sphingomyelinase. ${ }^{45}$

$\mathrm{Lp}$ (a) particles are susceptible to oxidative modification and scavenger receptor uptake, leading to intracellular cholesterol accumulation and foam cell formation, ${ }^{46}$ which contributes further to atherogenesis. The raised sialic acid content of $\mathrm{Lp}(\mathrm{a})$ is thought to contribute to the oxidative resistance of the native particle. ${ }^{47}$ The prothrombotic action of $\mathrm{Lp}(\mathrm{a})$ is, however, far more well established. Because of the structural homology with plasminogen, $\mathrm{Lp}(\mathrm{a})$ might have important antithrombolytic properties, which could contribute to the pathogenesis of atherothrombotic disease. For example, Lp(a) binding to immobilised fibrinogen and fibrin results in the inhibition of plasminogen binding to these substrates. ${ }^{48}$ In addition, $\mathrm{Lp}$ (a) competes with plasminogen for its receptors on endothelial cells, leading to diminished plasmin formation, thereby delaying clot lysis and favouring thrombosis. ${ }^{48}$ The high affinity of $\mathrm{Lp}(\mathrm{a})$ for fibrin provides a mechanistic basis for their frequent colocalisation in atherosclerotic plaques. ${ }^{49} 50$

In vitro studies indicate that $\mathrm{Lp}$ (a) enhances the synthesis of plasminogen activator inhibitor 1 (PAI-1) by endothelial cells. PAI-1 is the main inhibitor of the fibrinolytic system. ${ }^{51}$ Another potentially important action of $\mathrm{Lp}(\mathrm{a})$ is that by displacing plasminogen from the surfaces of macrophages in atherosclerotic plaques, it reduces the activation of latent transforming growth factor $\beta$ (TGF- $\beta$ ). In the absence of activated TGF- $\beta$, cytokines might induce smooth muscle cell proliferation and the transformation of these cells to a more atherogenic cellular phenotype. ${ }^{52}$

The relative importance of oxidation or thrombogenic mechanisms is difficult to establish at this stage.

THE RELATION BETWEEN Lp(a) AND ATHEROSCLEROSIS

The question of whether $\mathrm{Lp}$ (a) plays a primary or synergistic role in atherosclerosis has been investigated recently. ${ }^{53}$ Almost all cross sectional and retrospective studies involving white men have shown an increased risk of coronary, peripheral, and cerebrovascular atherosclerotic disease associated with plasma Lp(a) concentrations greater than the 80th centile $(>250$ $300 \mathrm{mg} /$ litre). Prospective studies have provided controversial data. However, cross sectional and retrospective studies could be misleading because of selection bias or the effect that the disease itself can have on the studied parameter. ${ }^{53}$ Furthermore, storage of the samples and the use of suboptimal $\operatorname{Lp}(\mathrm{a})$ assays might interfere in the interpretation of the results. ${ }^{53}$ Nevertheless, most of the more recent prospective studies revealed a modest significant association between IHD and raised plasma Lp(a) concentrations. ${ }^{54-56}$

Another question that has been raised is whether atherosclerosis itself can cause high plasma $\mathrm{Lp}$ (a) concentrations. In this context, it is relevant that patients with IHD as well as children with a positive family history of IHD commonly exhibit small apo(a) phenotypes. ${ }^{42} 57$ This association of small apo(a) isoforms with higher $\mathrm{Lp}(\mathrm{a})$ concentrations suggests that raised $\mathrm{Lp}$ (a) concentrations antedate the atherosclerotic process. ${ }^{53}$

\section{$\mathrm{Lp}(\mathrm{a})$ and other thrombotic risk factors} Lp(a) AND FIBRINOGEN

Serum $\mathrm{Lp}(\mathrm{a})$ concentrations correlate significantly with plasma fibrinogen values in some, but not all, studies. ${ }^{58} 59$ This association is of interest because platelet activity is enhanced by fibrinogen, ${ }^{60}{ }^{61}$ and raised plasma fibrinogen concentrations are predictors of vascular events, both in healthy populations and in 
patients with IHD. ${ }^{62}$ In the Goettingen risk incidence and prevalence study (GRIPS), $\mathrm{Lp}$ (a) and fibrinogen concentrations proved to be of value in estimating the risk of myocardial infarction. ${ }^{63}$ Data from GRIPS and the European concerted action on thrombosis and disabilities (ECAT) studies support the hypothesis that fibrinogen is a particularly important risk factor for acute coronary events in patients with asymptomatic or overt IHD. ${ }^{64} 65$

There is strong evidence that fibrinogen is an independent risk factor for ischaemic atherothrombotic stroke. ${ }^{66}$ Fibrinogen values remain significantly raised after stroke, and are associated with an increased risk of recurrent vascular events. ${ }^{67}$ In patients with stroke, fibrinogen is associated with a decrease in white blood cell elasticity and red blood cell deformability, and an increase in plasma erythrocyte viscosity. ${ }^{68}$ Fibrinogen also promotes platelet aggregation and consumption in the ischaemic area in patients with stroke. ${ }^{69}$

In this context, fibric acid derivatives can reduce the circulating concentrations of $\operatorname{Lp}(a)$ and fibrinogen. ${ }^{64} 7071$ Therefore, the platelet inhibitory activity of fibric acid derivatives could be mediated via their action on lipid fractions (mainly TG and HDL), Lp(a), and/or fibrinogen. ${ }^{72}{ }^{73}$ The preliminary results of two recently presented fibrate trials are discussed below.

\section{Lp(a) AND HOMOCYSTEINE}

Even a moderate rise in the circulating concentration of homocysteine is associated with an increased risk of atherosclerosis and arterial or venous thrombosis. ${ }^{74}{ }^{75}$ There is epidemiological evidence showing that the risk of vascular events is increased in those with a concomitant rise of both $\operatorname{Lp}(\mathrm{a})$ and homocysteine. ${ }^{76}$ This association is of interest because both $\mathrm{Lp}(\mathrm{a})$ and homocysteine can have unwanted effects on platelets as well as on coagulation and fibrinolysis. Experimental data showed that hyperhomocysteinaemia is associated with increased platelet aggregability and thromboxane $\mathrm{A}_{2}$ $\left(\mathrm{TXA}_{2}\right)_{\text {release. }}{ }^{77} \mathrm{TXA}_{2}$ is a vasoconstrictor and a promoter of platelet aggregation. Homocysteine has a low mitogenic effect on vascular smooth muscle cells, but it enhances the mitogenic properties of platelet derived growth factor BB (PDGF-BB). ${ }^{78}$ Of the PDGF stored in human platelets, $30 \%$ is in the PDGF-BB form; the remainder is in the PDGF-AB form. ${ }^{79}$

There is epidemiological evidence that homocysteine is a strong predictor of ischaemic stroke. ${ }^{80}$ Moderate increases in homocysteine values (even within the population reference range) are associated with vascular pathology through a variety of mechanisms, including atherosclerosis and thrombosis. ${ }^{80}$ Homocysteine concentrations are influenced by renal function and vitamin $B_{12}$ status in patients with stroke. $^{81}$

Homocysteine, $\mathrm{Lp}(\mathrm{a})$, and fibrinogen probably interact to promote atherosclerosis. ${ }^{82}$ Therefore, it is likely that their clustering increases the risk of vascular events. This possibility deserves further investigation. There is already evidence, from epidemiological studies, indicating that the dyslipidaemia + raised $\mathrm{Lp}(\mathrm{a})$ and dyslipidaemia + raised fibrinogen combinations increase the risk of vascular events. ${ }^{638384}$

Lp(a) AND OTHER CARDIOVASCULAR RISK FACTORS Plasma concentrations of $\mathrm{Lp}(\mathrm{a}), \mathrm{TC}, \mathrm{TG}$, and very low density lipoprotein (VLDL) cholesterol are higher in patients with hypertension. ${ }^{85} 86$ It has been shown recently that raised $\mathrm{Lp}(\mathrm{a})$ concentrations and the presence of low molecular weight apo(a) isoforms are strong and independent risk factors for IHD in patients with hypertension. ${ }^{87}$

The data on $\mathrm{Lp}$ (a) concentrations in diabetes are largely based on small studies and are conflicting. Larger studies and those including apo(a) phenotype analysis suggest that $\mathrm{Lp}(\mathrm{a})$ concentrations are not different from those in patients without diabetes, or are at most only moderately raised in patients with insulin dependent diabetes. ${ }^{85}$ However, there is evidence that $\operatorname{Lp}(\mathrm{a})$ concentrations are raised in patients with diabetes associated renal function impairment. Furthermore, atherosclerotic complications in patients with diabetes are associated with higher $\mathrm{Lp}(\mathrm{a})$ concentrations. ${ }^{85}$

Cigarette smoking is associated with increased values of LDL, TG, and VLDL and decreased concentrations of HDL. However, no direct effect on $\mathrm{Lp}(\mathrm{a})$ values has been reported in smokers. ${ }^{88}$

There is some controversy about the effect of obesity on $\mathrm{Lp}(\mathrm{a})$. In one study, $\mathrm{Lp}$ (a) concentrations were not influenced by obesity, visceral fat content, or weight loss after a very low energy diet. ${ }^{89}$ However, there is also some evidence that obese individuals have higher $\mathrm{Lp}$ (a) values and that weight loss (by diet or surgical intervention) is associated with a significant reduction in these values..$^{90} 91$ The mechanism(s) responsible for these changes remain(s) to be defined.

\section{Lipid variables and the risk of stroke}

\section{TC AND STROKE}

Early studies did not suggest that raised serum TC values consistently predict stroke related mortality. ${ }^{92}{ }^{93}$ Indeed, in some studies, TC values were inversely related to death as a result of stroke. ${ }^{94}$ In a meta-analysis of 13000 strokes in a total of 450000 people, no significant association between serum TC concentrations and stroke was found. ${ }^{95}$ In the Framingham heart study, ${ }^{96}$ TC concentrations were positively related to stroke mortality in women aged less than 55 years, whereas a U-shaped association was seen in women older than 55, and an inverse relation between TC and short term (within five years) mortality in women older than 70 years of age. In Israel, Korn-Lubetzki et al found that patients with stroke had low serum TC and LDL cholesterol values. ${ }^{97}$ These early results might have been inconclusive in demonstrating an association between lipid concentrations and stroke because ischaemic and haemorrhagic strokes were not differentiated. 
Epidemiological surveys showed an inverse association between TC values and the risk of intracerebral haemorrhage, independently of age and sex. ${ }^{98-107}$ Specifically, 54385 Swedish men and women participated in a health survey with serum cholesterol and diastolic blood pressure determinations. ${ }^{101}$ The follow up period was 20.5 years (1964 to 1985). The relative risk for subarachnoid haemorrhage in men, but not in women, increased with decreasing TC values. ${ }^{101}$ In women, the relative risk for intracerebral haemorrhage was inversely related to TC values. For cerebral haemorrhage in men, the risk function was U-shaped. ${ }^{101}$ Adjustment for diastolic blood pressure did not significantly change the relation between the risk for any of the different stroke types and the cholesterol values. ${ }^{101}$ Furthermore, a large cohort (61 756 subjects aged 40 to 89 years) study was performed in the San Francisco-Oakland metropolitan area from 1977 to $1985 .{ }^{100}$ The average follow up period was 10.7 years. In this study, an association between low TC values and increased risk for intracerebral haemorrhage was confined to elderly men (aged 65 years or older).$^{100}$ In more recent studies, such as the multiple risk factor interventional trial (MRFIT), a positive relation between serum TC values and nonhaemorrhagic strokes was shown, whereas serum TC values were inversely related to intracranial haemorrhage. ${ }^{102} 103$ In a case control study, conducted from 1990 to 1992 in Italy, Di Mascio and colleagues ${ }^{107}$ showed a strong linear relation between TC concentrations and the risk for myocardial infarction $(\mathrm{p}<0.0001)$. However, a significant linear trend in risk was also found between TC values and ischaemic stroke $(\mathrm{p}<0.01) .{ }^{107}$

Although it has been shown that serum TC is an independent factor for stroke ${ }^{104}$ and transient ischaemic attacks (TIA), ${ }^{105}$ the relation between TC and ischaemic stroke does not seem to be as strong as it is with IHD, ${ }^{106}{ }^{107}$ perhaps because different pressure gradients and vessels are involved. When considering large studies (for example, the Honolulu heart study in migrants from Japan and the MRFIT screening study), an increase in nonhaemorrhagic stroke was seen at the highest, but not intermediate, concentrations of TC. ${ }^{106}$

TG CONCENTRATIONS AND STROKE

Interestingly, it has been shown that postprandial hypertriglyceridaemia is associated with carotid artery atherosclerosis. ${ }^{108}$ However, there is controversy regarding the association between serum TG values and the risk of stroke. ${ }^{5}$ Nevertheless, in the Copenhagen City heart study, ${ }^{109}$ a log linear association between serum TG concentrations and nonhaemorrhagic stroke was found (relative risk, $1.12 / 1 \mathrm{mmol} /$ litre increase in serum TG; $95 \%$ confidence interval, 1.07 to 1.16 ); this association was independent of age and sex.

HDL CHOLESTEROL AND STROKE

In general, most case control studies reported an inverse association between HDL cholesterol and stroke risk. ${ }^{5}$ Although no association was found in the Framingham study, ${ }^{110}$ in the Copenhagen City heart study ${ }^{109}$ a negative relation was evident (relative risk, 0.53; 95\% confidence interval, 0.34 to 0.83 ).

APOLIPOPROTEIN E PHENOTYPES AND STROKE Apolipoprotein E (apoE) phenotypes have been associated with strokes. ${ }^{111}$ Pedro-Bodet et al, in a case control study, ${ }^{111}$ showed that the frequency of the apoE4 gene is high in patients with ischaemic stroke. In addition, it has been shown that the apoE3/E3 phenotype has a "protective" association with stroke, because it was present more frequently in stroke free controls than in patients with ischaemic stroke. ${ }^{111}$ In contrast, the apoE2 genotype is a risk factor possibly expressed through any concurrent obesity, diabetes, or hypertension. ${ }^{112}$

\section{GEOGRAPHICAL VARIATION IN THE INCIDENCE OF} STROKE

It has been reported that in Japan and China, the age standardised annual death rate from stroke is greater than that of IHD, whereas in Northern Europe and the USA the IHD associated mortality is three to four times greater than the stroke related deaths. ${ }^{513}$ The increased stroke mortality in Japan might be related to a higher proportion of haemorrhagic strokes. ${ }^{113}$ In contrast, in Mediterranean countries, deaths as a result of both IHD and stroke display an approximate $1: 1$ ratio. ${ }^{113}$ Serum TC values, smoking, alcohol intake, and traditional diets account for these differences. ${ }^{5114}$ Unfortunately, we are not aware of extensive epidemiological studies that compared $\mathrm{Lp}$ (a) values in these nations. However, there is some evidence that median serum $\mathrm{Lp}$ (a) values are very similar in American white and Chinese individuals (90 and $80 \mathrm{mg} / \mathrm{litre}$, respectively). ${ }^{16}$ There also appeared to be a shift towards apo(a) alleles of larger sizes in the Chinese. ${ }^{16}$

\section{Lp(a) and stroke}

Apart from the well established risk factors for strokes (such as increasing age, hypertension, diabetes, smoking, or the presence of vascular disease), ${ }^{15}$ the possibility that $\mathrm{Lp}(\mathrm{a})$ is a risk factor for ischaemic stroke has been assessed in several (mainly retrospective) studies (table 1 ).

STUDIES SUPPORTING Lp(a) AS A RISK FACTOR FOR STROKE

In a case control study, serum $\mathrm{Lp}$ (a) values were significantly $(p<0.001)$ higher in patients with ischaemic stroke compared with healthy individuals (median, $95 v$ $50 \mathrm{mg} /$ litre). ${ }^{115}$ This difference was also evident in a subgroup of subjects aged 30 to 69 years $(\mathrm{p}<0.001) .{ }^{115}$

Lindgren et al determined lipid variables in 131 patients six months after their stroke. ${ }^{116}$ These patients had higher TG and Lp(a) values and lower TC, LDL, and HDL concentrations compared with controls.

Vavernova et al investigated $\mathrm{Lp}(\mathrm{a})$ values in 45 patients with stroke (younger than 55 years of age) and their first degree relatives. ${ }^{117}$ They 
reported that $\mathrm{Lp}(\mathrm{a})$ values were genetically conditioned in patients with ischaemic strokes.

With regard to the genetic control of plasma $\mathrm{Lp}$ (a) concentrations, Jurgens et al determined $\mathrm{Lp}$ (a) values and apo(a) phenotypes in a consecutive series of 265 patients with ischaemic stroke in comparison with 288 controls. ${ }^{118}$ They suggested that raised $\mathrm{Lp}(\mathrm{a})$ concentrations comprise a primary risk factor associated with the presence of this disease. In addition, they demonstrated that low molecular weight $(\leqslant 580 \mathrm{kDa})$ apo(a) isoforms were more frequent in the patients with stroke $(42.65 \%$ v $16.73 \% ; \mathrm{p}<0.001)$. Peynet et al evaluated the $\mathrm{Lp}$ (a) concentration and apo(a) isoform size in 90 young patients (mean age: 37.4 years) with acute cerebral ischaemia compared with those of age and sex matched controls. ${ }^{119}$ They showed that serum $\operatorname{Lp}(\mathrm{a})$ concentrations were significantly increased in the patients with stroke $(p=0.009)$. However, there was no difference in the apo(a) isoform distribution between patients and controls. ${ }^{119}$

Van Kooten and colleagues ${ }^{120}$ assessed Lp(a) concentrations in 151 consecutive patients admitted because of acute cerebral ischaemia. They found that in about one third of patients $\mathrm{Lp}$ (a) values were significantly raised, but this increase was not associated with the cardiovascular risk profile, stroke characteristics, or the prognosis.

In a recent cross sectional study, $\mathrm{Lp}(\mathrm{a})$, PAI-1, and tPA were determined in patients with and without a history of stroke. ${ }^{121}$ After studying a total of 210 patients (half with a history of ischaemic stroke), a relation between $\mathrm{Lp}$ (a) and cerebral ischaemia was found. This was limited to individuals below 70 years with raised (> $500 \mathrm{mg} /$ litre) plasma $\mathrm{Lp}$ (a) values. ${ }^{121}$

Nagayama et al, in a case control study, investigated $\mathrm{Lp}(\mathrm{a})$ values in patients after a mean period of 27 months since their stroke. ${ }^{122}$ $\mathrm{Lp}$ (a) was a crucial and independent risk factor for ischaemic stroke, but not for lacunar stroke $\left(<1 \mathrm{~cm}^{2}\right.$ in size), especially in young adults. ${ }^{122}$

Peng et al investigated the relation between serum lipids, apoE genotypes, and the risk of ischaemic stroke. ${ }^{123}$ They studied 90 patients who experienced an acute ischaemic stroke versus 90 healthy individuals. Serum $\operatorname{Lp}(\mathrm{a})$ concentrations and the apoE4 genotype were the prominent lipid predictors for ischaemic

Table 1 Studies evaluating the role of lipoprotein (a) as a risk factor for ischaemic stroke

\begin{tabular}{ll}
\hline For & Against \\
\hline Jurgens and Koltringer $(1987)^{115}$ & Hachinski et al $(1996)^{129}$ \\
Lindgren et al $(1992)^{116}$ & Glader et al $(1999)^{130}$ \\
Vavernova et al $(1993)^{117}$ & Alfthan et al l $^{\star}(1994)^{131}$ \\
Jurgens et al $(1995)^{118}$ & $\begin{array}{l}\text { Physicians' health study } \\
(1995)^{132}\end{array}$
\end{tabular}

Peynet et al (1999) $)^{119}$

Van Kooten et al (1996) $)^{120}$

Margaglione et al (1996) $)^{12}$

Nagayama et al (1994) ${ }^{122}$

Peng et al (1999) 123

Kariot al (199)

Kario et al (1996) ${ }^{126}$

ARIC study ${ }^{\star}(1994)^{12}$

Ichinose et al (1998) $)^{128}$

Studies are cited in the order that they appear in the text. Parentheses show the year of publication.

$\star$ Prospective study. stroke in addition to the more established risk factors such as hypertension, family history of stroke, and cigarette smoking. ${ }^{123}$

Asymptomatic, "silent", cerebral infarction has also attracted interest. A silent stroke is usually detected on incidental imaging (computed tomography scan, magnetic resonance imaging) in patients with no localised neurological signs. ${ }^{124}$ These findings are a predisposing factor for subsequent overt stroke. ${ }^{124}$ In most cases of silent infarction, lacunar strokes of less than $1 \mathrm{~cm}^{2}$ in size are detected in the basal ganglia in apparently healthy elderly people. ${ }^{125}$ These lesions are associated, in most reports, with advanced age and hypertension, and constitute a major cause of dementia. ${ }^{124} 125$ Kario and colleagues ${ }^{126}$ reported that silent multiple lacunar strokes in 178 asymptomatic, high risk, elderly Japanese patients (aged 44 to 93 years) were associated with a hypercoagulable state, endothelial damage, and significantly raised $\mathrm{Lp}(\mathrm{a})$ concentrations. The authors further subdivided the silent lacunar group into subgroups based on the number of lacunes (few lacunes, 1-2; moderate number, 3-4; numerous lacunes, $\geqslant 5$ ). Raised $\mathrm{Lp}(\mathrm{a})$ values (and particularly those $>300 \mathrm{mg} /$ litre) were more common in the "numerous lacune" than the "few lacune" subgroups. ${ }^{126}$

In the atherosclerosis risk in communities (ARIC) study, the association of $\mathrm{Lp}$ (a) with stroke was investigated in 15160 participants (4160 blacks and 11000 whites). ${ }^{127}$ In this study, $\mathrm{Lp}$ (a) was an independent risk factor for strokes and TIA, in both blacks and whites. The relative risk of $\mathrm{Lp}(\mathrm{a})$ associated stroke morbidity was not influenced by race. ${ }^{127}$

This evidence might indicate that the mean $\mathrm{Lp}$ (a) concentration is higher in patients with atherothrombotic brain infarction than in those with brain haemorrhage or lacunar infarction. ${ }^{128}$

Patients with IHD are at an increased risk of having a stroke. ${ }^{5}$ Thus, a selection bias might influence the relation between $\mathrm{Lp}(\mathrm{a})$ and risk of stroke because of an association between IHD and $\operatorname{Lp}(\mathrm{a})$ values.

STUDIES NOT SUPPORTING Lp(a) AS A RISK FACTOR FOR STROKE

The link between $\mathrm{Lp}(\mathrm{a})$ and stroke has been disputed by some investigators. Hachinski et $a l,{ }^{129}$ in a case control study, determined lipid variables, including $\mathrm{Lp}(\mathrm{a})$, in 90 patients with stroke or TIA of atherothrombotic origin. Increased LDL and TG concentrations correlated with atherothrombotic stroke risk, whereas there was no significant difference in the $\mathrm{Lp}$ (a) concentrations or the distribution of apoE phenotypes among patients and controls. ${ }^{129}$

The possibility of predicting ischaemic stroke by the determination of plasma $L p(a)$ concentrations and antibodies to Chlamydia pneumoniae was investigated by Glader et al. ${ }^{130}$ They studied 101 subjects who had suffered an ischaemic cerebral infarction and 201 controls. No association between baseline plasma Lp(a) values, the presence of anti-C pneumoniae antibodies, and future ischaemic cerebral infarc- 
tions was found. There was no evidence of an interactive effect between high $\mathrm{Lp}(\mathrm{a})$ values and anti- $C$ pneumoniae antibody titres. ${ }^{130}$

In a prospective study in Finland, no association was found between $\mathrm{Lp}(\mathrm{a})$ or homocysteine values and atherosclerotic disease (myocardial infarction or stroke) in logistic regression analyses among 7424 men and women aged 40-60 years without atherosclerotic disease at baseline. ${ }^{131}$ There were 134 events (myocardial infarction or stroke) in men and 131 in women. ${ }^{131}$ However, the lack of association between homocysteine values and the myocardial infarction/stroke end point might have been the result of the exceptionally low gene frequency predisposing to homocysteinaemia in Finland. ${ }^{131}$

A cohort of 14916 predominantly white, healthy, middle aged male physicians (physicians' health study) was followed prospectively for a period of 7.5 years. ${ }^{132}$ These subjects had no previous history of stroke, TIA, or myocardial infarction. During follow up, 198 physicians developed a stroke (155 thromboembolic, 35 haemorrhagic, and eight indeterminate). ${ }^{132}$ Their samples were analysed for $\mathrm{Lp}(\mathrm{a})$ together with paired controls, matched for age and smoking habit. Among the subjects participating in the study, no association between baseline plasma concentration of $\mathrm{Lp}$ (a) and future risk of total (all types of stroke) or thromboembolic stroke was found. ${ }^{132}$

\section{Atherosclerotic lesions in intracranial vessels}

LIPIDS AND ATHEROSCLEROSIS OF THE CEREBRAL ARTERIES

Evidence from experimental data suggested that the intracranial arteries are relatively resistant to cholesterol related endothelial damage. ${ }^{133-135}$ Thus, studies in primates failed to show an association between the hyperlipidaemic state and the development of atherosclerosis in intracranial arteries. ${ }^{133}$ Studies with cynomolgus and rhesus monkeys fed a hyperlipidaemic diet for eight to 12 months showed that the atherosclerotic lesions in their carotid arteries were more extensive than those in the basilar, vertebral, and middle cerebral arteries. ${ }^{134}$ However, the coexistence of hypertension and hypercholesterolaemia resulted in accelerated atherosclerosis of intracranial arteries in rat models. ${ }^{135}$

Studies based on human necropsies have shown that atherosclerotic changes in cerebral arteries make their appearance 20 years later than in the coronary arteries. ${ }^{136}$ Differences in the prevalence and extent of atherosclerotic lesions in the aorta and coronary or cerebral arteries were observed between different age and race groups. Black individuals and older people tend to have more extensive cerebral atherosclerosis. ${ }^{136}$ Interestingly, Postiglione and colleagues $^{137}$ reported that no atherosclerotic lesions were found in the cerebral arteries of young patients with homozygous familial hypercholesterolaemia, despite a severe involvement of all the other vascular beds.

It has been proposed that the paucity of pinocytic vesicles in the endothelium of cerebral arteries, their rich innervation, and the lower distending pressures make these vessels more resistant to hyperlipidaemia compared with coronary or peripheral arteries. ${ }^{136}$

LIPIDS AND ATHEROSCLEROTIC CHANGES IN CAROTID ARTERIES

In a recent study of 79 patients, Landray et al showed that age and smoking history predicted carotid atherosclerosis, whereas the LDL score was of a borderline significance. ${ }^{138}$ Furthermore, there was evidence that small, dense LDL subfractions were associated with carotid atherosclerosis and might be a modifiable risk factor for strokes and IHD. ${ }^{138}$

In an experimental model of occlusive arterial thrombus formation in cynomolgus monkeys, high $\mathrm{Lp}$ (a) values were associated with permanent cessation of flow and occlusive arterial thrombosis. ${ }^{139}$ Analysis of the damaged arterial segments indicated incorporation of $\mathrm{Lp}$ (a) into the adventitia, media, and intima. ${ }^{139}$

Jurgens and Koltringer ${ }^{140}$ studied 808 randomly selected patients (with positive stroke history as well as asymptomatic subjects). Plasma $\mathrm{Lp}(\mathrm{a})$ values correlated with carotid atherosclerosis in subjects younger than 60 years of age. ${ }^{140}$

It has been suggested that apo(a) can cause endothelial dysfunction by enhancing lipid deposition in vessel walls, inhibiting fibrinolysis, and modulating smooth muscle cell proliferation. ${ }^{26} \quad$ Moreover, Watts and colleagues $^{141}$ measured lipid variables (including $\mathrm{Lp}(\mathrm{a}))$ in 49 white patients with TIA undergoing carotid angiography. Raised Lp(a) concentrations were a significant determinant of the extent of carotid atherosclerosis. Therefore, the measurement of serum $\mathrm{Lp}$ (a) concentrations might help identify patients with an increased risk of stroke. ${ }^{141}$

Lipid associations with stroke might result from emboli originating in the aortic arch. ${ }^{142} 143$ However, it is still not clear whether lipid lowering treatment greatly reduces the risk of this complication of atherosclerotic disease. Endothelial dependent vasomotor tone is also related to lipoprotein values but the implications for cerebral events are not yet determined. ${ }^{144}$

\section{Can serum $L p(a)$ values be reduced?}

DIETARY MODIFICATION

Diet is not thought to influence $\operatorname{Lp}(\mathrm{a})$ values to any great extent. However, saturated and n-3 polyunsaturated fatty acids may slightly reduce Lp(a) values. Thus, a diet rich in palm oil has been reported to reduce $\mathrm{Lp}$ (a) concentrations by approximately $10 \% .{ }^{145}$ In one study, a short term diet with n-3 polyunsaturated fatty acids had no significant effect on $\mathrm{Lp}$ (a) concentrations, but long term administration reduced these values by as much as $20 \% .{ }^{146}$

\section{NICOTINIC ACID}

Nicotinic acid has a favourable, although inconsistent, effect on $\mathrm{Lp}$ (a) concentrations. ${ }^{59}$ However, this drug is difficult to tolerate at the high doses required. 
STATINS

Interestingly, a recently published overview of all randomised trials of statin treatment demonstrated that large reductions in TC values are associated with significant benefit on stroke and total mortality. ${ }^{5}$ All the patients had atherosclerotic vascular disease, itself a major risk factor for stroke. ${ }^{5}$ In the Scandinavian simvastatin survival study (4S), simvastatin treatment (20 to $40 \mathrm{mg}$ daily) reduced the combined incidence of TIA and stroke by $29 \%{ }^{4}$ Similarly, in the cholesterol and recurrent events (CARE) trial, pravastatin (40 mg daily) reduced the relative risk of stroke by as much as $32 \%$, over a median follow up period of five years. ${ }^{147}$ In the long term intervention with pravastatin in ischaemic disease (LIPID) study, pravastatin (40 $\mathrm{mg}$ daily) reduced the relative risk of stroke by $19 \%{ }^{148}$ These beneficial effects on stroke and myocardial infarction occur against a background of statins causing a slight increase in circulating $\mathrm{Lp}(\mathrm{a})$ values..$^{35-37}$ The fact that statins do not reduce $\mathrm{Lp}$ (a) concentrations supports the concept that the LDL receptor does not play an important part in the catabolism of $\mathrm{Lp}(\mathrm{a}) .^{26}$

FIBRATES

Fibric acid derivatives exert as favourable an effect on HDL and TG concentrations as on LDL quantity and quality. These drugs also reduce fibrinogen and possibly $\mathrm{Lp}(\mathrm{a})$ values. ${ }^{33}{ }^{34}$ It is tempting to speculate that the favourable clinical end points observed in two recently presented fibrate based clinical trials might be attributable, at least in part, to these beneficial actions. Thus, in the bezafibrate infarction prevention study (BIP), a reduction in the highest fibrinogen concentrations was associated with a decrease in the incidence of the primary end points: cardiac death and ischaemic stroke. ${ }^{149}$ Unfortunately, serum $\mathrm{Lp}$ (a) values were not monitored. In BIP, there was a very small reduction $(6.5 \%)$ in serum $\mathrm{LDL}$ values. This reduction in LDL would not be expected to account for the results of this trial. However, because the clinical benefit was limited to patients with raised TG (with or without reduced concentrations of HDL) it is possible that this effect is related to a pronounced rise in HDL and fall in TG values. Another possibility is a fibrate induced reduction in oxidised LDL production because this form of LDL is highly atherogenic. The results of BIP are supported by those of the veterans affairs HDL intervention trial (VA-HIT). In this trial ${ }^{150}$, gemfibrozil (1200 mg daily) reduced total reported stroke from $6.9 \%$ in the placebo group to $5.1 \%(\mathrm{p}=0.05)$ in the treated group. TIA in the same trial were reduced from $4.2 \%$ to $1.7 \%(\mathrm{p}=0.001)$, and carotid endarterectomy was significantly $(\mathrm{p}=0.001)$ reduced (gemfibrozil, $1.3 \%$; placebo, $3.5 \%$ ); LDL values were essentially unchanged.

DIABETES, ANTIHYPERTENSIVE DRUGS, AND HORMONAL TREATMENT

Optimising body weight and tight glycaemic control may beneficially influence $\mathrm{Lp}$ (a) values in patients with type 1 and type 2 diabetes. ${ }^{151}$ This effect is in part linked to TG metabolism, which is impaired in type 2 diabetes, as well as the glycosylation of $\mathrm{Lp}(\mathrm{a})$, which interferes with its catabolism. ${ }^{151}$ In this setting, it has been shown that treating dyslipidaemia in patients with diabetes (for example, by using a fibrate) improves the lipid profile and lowers the incidence of IHD. ${ }^{152}$

Antihypertensive agents can affect plasma fibrinogen and $\operatorname{Lp}(\mathrm{a})$ values as well as the lipid profile. ${ }^{153}$ These additional properties might influence the choice of medication, especially in patients where these predictors of vascular events (including stroke) are raised. ${ }^{153}$

Hormonal replacement therapy (HRT) in postmenopausal women is probably associated with a reduction in the risk of developing coronary artery disease. ${ }^{154}$. HRT favourably affects cholesterol, Lp(a), and homocysteine concentrations, especially in those women with the highest concentrations of these risk factors. ${ }^{155}$ Several, but not all, studies showed that thyroid replacement treatment decreases $\mathrm{Lp}(\mathrm{a})$ concentrations, probably because of an effect upon apo(a) production, or possibly $\mathrm{Lp}(\mathrm{a})$ assembly. $^{28}$

FUTURE “THERAPEUTIC" DIRECTIONS

$\mathrm{Lp}$ (a) undergoes further modifications after entry into the arterial wall. Whether these changes influence cardiovascular risk or are mere epiphenomena is yet to be determined. However, post-translational events (such as oxidation and proteolysis) could become potential targets for therapeutic intervention. ${ }^{26}$

Any reliable evaluation of a therapeutic intervention to reduce $\mathrm{Lp}(\mathrm{a})$ values must rely on a reproducible and standardised assay with appropriate calibration and data analysis appropriate to a highly skewed variable. At present, this objective has not been completely achieved. $^{26}$ Initial studies involving $\mathrm{Lp}(\mathrm{a})$ measurement may have used even less reliable assays..$^{53}$ Clearly, this assay problem is relevant to epidemiological studies. It might also be appropriate to convert data for LDL for the quantity incorporated into $\mathrm{Lp}(\mathrm{a})$ molecules. This amount might not be trivial in patients with high $\mathrm{Lp}(\mathrm{a})$ concentrations.

Studies assessing the risk attributed to $\mathrm{Lp}$ (a) must consider the contribution of other predictors of vascular events (such as hypertension, dyslipidaemia, fibrinogen, and homocysteine). 6376838487156

\section{Concluding remarks}

The evidence that $\mathrm{Lp}(\mathrm{a})$ is a strong predictor for ischaemic stroke is contradictory. Apart from the lack of universally accepted, standardised methods for determination, Hobbs and White proposed several factors that might contribute to the existing confusion in attributing risk to $\mathrm{Lp}(\mathrm{a}) .^{53}$ These include: (1) small sample sizes unable to determine the relation between apo(a) phenotypes and $\mathrm{Lp}$ (a) concentrations, (2) different ethnic groups, (3) the influence of oestrogens in women participating in studies, (4) plasma storage before $\mathrm{Lp}$ (a) determination, (5) inappropriate methods of data analysis, and 
(6) selection bias. ${ }^{53}$ However, on balance, there is evidence that raised circulating $\mathrm{Lp}(\mathrm{a})$ concentrations are associated with an increased risk of vascular events. Furthermore, other risk factors (such as dyslipidaemia or raised homocysteine values) enhance the risk attributed to $\mathrm{Lp}(\mathrm{a})$. Therefore, the association between high $\mathrm{Lp}$ (a) values and atherosclerotic complications might be weaker in prospective studies than in cross sectional studies. In the latter, the presence of the disease is a prerequisite and, thus, other risk factors could significantly contribute to the atherosclerotic burden. ${ }^{53}$

The determination of apo(a) isoforms in epidemiological surveys (especially prospective studies), although expensive, might be necessary to define the risk load attributable to $\mathrm{Lp}$ (a). Consideration of other risk factors that might be related to plasma $\operatorname{Lp}(\mathrm{a})$ values (for example, fibrinogen), or act synergistically with $\mathrm{Lp}$ (a) (for example, LDL), will be mandatory in these studies. The genetic and environmental factors controlling the circulating concentrations of $\mathrm{Lp}(\mathrm{a})$ also need further definition. Our understanding of the vascular pathology of $\mathrm{Lp}$ (a) remains relatively poor.

Reducing the circulating values of $\mathrm{Lp}(\mathrm{a})$ might prove difficult. One approach is to deal aggressively with all the other modifiable risk factors.

1 American Heart Association. Heart and stroke facts: 1994 statistical supplement. Dallas: American Heart Association, 1993.

2 West of Scotland Coronary Prevention Study Group. West of Scotland coronary prevention study: identification of high-risk groups and comparison with other cardiovascular intervention trials. Lancet 1996;348:1339-2.

3 The Pravastatin Multinational Study Group for Cardiac Risk Patients. Effects of pravastatin in patients with serum Risk Patients. Effects of pravastatin in patients with serum $300 \mathrm{mg} / \mathrm{dl}$ ) plus two additional atherosclerotic risk factors $300 \mathrm{mg} / \mathrm{dl}$ ) plus two additiona

4 Scandinavian Simvastatin Survival Study Group. Randomised trial of cholesterol lowering in 4444 patients with simvastatin survival study (4S). Lancet 1994;344:1383-9.

5 Papadakis JA, Mikhailidis DP, Winder AF. Lipids and stroke: neglect of a useful preventive measure? Cardiovas Res 1998;40:265-71.

6 Dahlen G. Lp(a) lipoprotein in cardiovascular disease. Atherosclerosis 1994;108:111-26.

7 Cheng SW, Ting AC, Wong J. Lipoprotein (a) and its relationship to risk factors and severity of atherosclerotic
peripheral vascular disease. Eur f Vasc Endovasc Surg 1997; peripheral $14: 17-23$.

8 Konemari G. Lipoprotein(a) and other risk factors for cerebral infarction. Hiroshima f Med Sci 1995;44:65-77.

9 Huby T, Chapman J, Thillet J. Pathophysiological implication of the structural domains of lipoprotein(a). Atheroscle rosis $1997 ; 133: 1-6$.

10 Ikeo K, Takahashi K, Gojobori T. Different evolutionary histories of kringle and protease domains in serine proteases: a typical example of domain evolution. $\mathcal{f} \mathrm{Mo}$ Evol 1995;40:331-6.

11 McLean JW, Tomlinson JE, Kuang WJ, et al. cDNA sequence of human lipoprotein(a) is homologous to plasminogen. Nature 1987;330:132-7.

12 Byrne C, Lawn R. Studies on the structure and function of the apolipoprotein(a) gene. Clin Genet 1994;46:34-41.

13 Van der Hoek YY, Wittekoek ME, Beisiegel U, et al. The apolipoprotein(a) kringle IV repeats which differ from the major repeat kringle are present in variably-sized isoforms. Hum Mol Genet 1993;2:361-6.

14 Marcovina SM, Hobbs HH, Albers JJ. Relation between number of apolipoprotein(a) kringle 4 repeats and mobility of isoforms in agarose gel: basis for a standardized isoform nomenclature. Clin Chem 1996;42:436-9.

15 Boerwinkle E, Leffert C, Lin J, et al. Apolipoprotein(a) gene accounts for greater than $90 \%$ of the variation in plasma
lipoprotein(a) concentrations. F Clin Invest 1992;90:52-60.

16 Gaw A, Boerwinkle E, Cohen JC, et al. Comparative analysis of the apo(a) gene, apo(a) glycoprotein, and plasma concentrations of $\operatorname{Lp}(a)$ in three ethnic groups. Evidence for no common "null" allele at the apo(a) locus. 7 Clin for no common "null"

17 Craig W, Ledue T. Lipoprotein(a) and the acute phase response. Clin Chim Acta 1992;210:231-2.
18 Bruckert E, Davidoff P, Grimaldi A, et al. Increased serum levels of lipoprotein (a) in diabetes mellitus and their reduction with glycemic control. $₹ A M A$ 1990;263:35-6.

19 Kronenberg F, Koenig P, Neyer U, et al. Multicenter study of lipoprotein(a) and apolipoprotein(a) phenotypes in patients with end-stage renal disease treated by hemodialysis or continuous ambulatory peritoneal dialysis. $7 \mathrm{Am}$ Soc Nephrol 1995;6:110-20.

20 Siamopoulos KC, Elisaf MS, Bairaktari HT, et al. Lipid parameters including lipoprotein(a) in patients undergoing CAPD and hemodialysis. Perit Dial Int 1995;15:342-7.

21 Milionis H, Elisaf M, Tselepis A, et al. Apolipoprotein (a) phenotypes and lipoprotein (a) concentrations in patients with renal failure. Am f Kidney Dis 1999;33:1100-6.

22 Stevingel P, Berglund L, Heimbuerger O, et al. Lipoprotein(a) in nephrotic syndrome. Kidney Int 1993;44:111623.

23 Elisaf MS, Bairaktari HT, Tzallas CS, et al. Increased lipoprotein (a) levels in patients with proteinuria. Cardiovascular Risk Factors 1996;6:289-93.

24 Wright LC, Sullivan DR, Muller M, et al. Elevated apolipoprotein(a) levels in cancer patients. Int $\mathcal{F}$ Cancer 1989;43: 241-4.

25 Engler H, Riesen W. Effect of thyroid function on concentration of lipoprotein(a). Clin Chem 1993;39:24669.

26 Scanu AM. Atherothrombogenicity of lipoprotein (a): the debate. Am f Cardiol 1998;82:26Q-33Q.

27 Feely J, Barry M, Keeling PWN, et al. Lipoprotein(a) in cirrhosis. BMF 1992;304:545-6.

28 Kung AWC, Pang RWC, Lauder I, et al. Changes in serum lipoprotein(a) and lipids during treatment of hyperthyroidism. Clin Chem 1995;41;226-231.

29 Carlson L, Hamsten A, Asplund A. Pronounced lowering of serum levels of lipoprotein $\mathrm{Lp}(\mathrm{a})$ in hyperlipidemic subjects treated with nicotinic acid. F Intern Med 1989;226: jects treat 6 .

30 Elisaf $\mathrm{M}$, Bairaktari $\mathrm{H}$, Tzallas $\mathrm{Ch}$, et al. The beneficial effect of tamoxifen on the serum lipoprotein Lp(a) levels: an additional anti-atherogenic property. Anticancer Res 1996;16:2725-8.

31 Farish E, Spowart K, Barnes JF, et al. Effects of postmenopausal hormone replacement therapy on lipoproteins rosis 1996;126:77-84.

32 Crook D, Sidhu M, Seed M, et al. Lipoprotein Lp(a) levels are reduced by danazol, an anabolic steroid. Atherosclerosis 1992;92:41-7.

33 Maggi FM, Poglionica MR, De Michele L, et al. Bezafibrate lowers elevated plasma levels of fibrinogen and lipoprotein (a) in patients with type IIa and IIb dyslpoproteinaemia. Nutr Metab Cardiovasc Dis 1994;4:215-20.

34 Mikhailidis DP, Ganotakis ES, Spyropoulos KA, et al. Prothrombotic and lipoprotein variables in patients attending a cardiovascular risk management clinic: response to ciprofibrate of lifestyle advice. Int Angiol 1998; 17:225-33.

35 Kostner GM, Gavish D, Leopold B, et al. HMG CoA reductase inhibitors lower LDL cholesterol without reducing Lp(a) levels. Circulation 1989;80:1313-19.

36 Hunninghake DB, Stein EA, Mellies MJ. Effects of one year of treatment with pravastatin, an HMG-CoA reductase inhibitor, on lipoprotein(a). F Clin Pharmacol 1993;33:57480.

37 Nair DR, Papadakis JA, Jagroop IA, et al. Statins and fibrinogen. Lancet 1998;351:1430

38 Marcovina SM, Albers JJ, Jacobs DR, et al. Lipoprotein(a) concentrations and apolipoprotein(a) phenotypes in Caucasians and African Americans. Arterioscler Thromb 1993; 13:1037-45.

39 Asanuma Y, Kawai S, Aoshima H, et al. Serum lipoprotein (a) and apolipoprotein (a) phenotypes in patients with rheumatoid arthritis. Arthritis Rheum 1999;42:443-47.

40 Gaw A, Brown EA, Ford I for the West of Scotland Coronary Prevention Study Group. Impact of apo(a) length polymorphism and the control of plasma Lp(a) concentrations. 1998;18:1870-6.

41 Suzuki K, Kuriyama M, Saito T, et al. Plasma lipoprotein(a) levels and expression of the apolipoprotein(a) gene are dependent on the nucleotide polymorphism in its 5'flanking region. $\mathcal{F}$ Clin Invest 1997;99:1361-6.

42 Sandholzer C, Saha N, Kark JD, et al. Apo(a) isoforms predict risk for coronary heart disease. A study in six populations. Arterioscler Thromb 1992;12:1214-26.

43 Rath M, Niedorf A, Rablin T, et al. Detection and quantification of lipoprotein(a) in the arterial wall of 107 coronary bypass patients. Arteriosclerosis 1989:9.579-92.

44 Kostner GM, Bihara Varga M. Is atherogenicity of $\mathrm{Lp}(\mathrm{a})$ caused by its reactivity with proteoglycans? Eur Heart $\mathcal{f}$ 1990;11(suppl E):184-9.

45 Tabas I, Li Y, Brocia RW, Xu SW, et al. Lipoprotein lipase and sphingomyelinase synergistically enhance the association of atherogeneic lipoproteins with smooth muscle cell and extracellular matrix. A possible mechanism for low density lipoprotein and lipoprotein (a) retention and macrophage foam cell formation. F Biol Chem 1993;268:2041932.

46 De Rijke YB, Jurgens G, Hessels EM, et al. In-vivo fate and scavenger receptor recognition of oxidised lipoprotein (a) isoforms in rats. 7 Lipid Res 1992;33:1315-25.

47 Chapman MJ, Huby T, Nigon F, et al. Lipoprotein (a): implication in atherothrombosis. Atherosclerosis 1994; 110(suppl):S69-75. 
48 Aznar J, Estelles A, Breto M, et al. Euglobulin clot lysis induced by tissue type plasminogen activator in subjects with increased levels and different isoforms of lipopro$1993 ; 72: 459-65$

49 Smith EB, Cochran S. Factors influencing the accumulation in fibrous plaques of lipid derived from LDL. II. Preferentia immobilisation of Lp(a). Atherosclerosis 1990;84:173-81.

50 Beisiegel U, Niendorf A, Wolf K, et al. Lipoprotein (a) in the arterial wall. Eur Heart f 1990;11(suppl): 174-83.

51 Edelberg J, Reilly C, Pizzo S. The inhibition of tissue type plasminogen activator by plasminogen activator inhibitor-1. The effects of fibrinogen, heparin, vitronectin and lipoprotein(a). F Biol Chem 1991;4:2459-65.

52 Graigner DJ, Kirschenlhor HL, Metcalf JC, et al. Proliferation of human smooth muscle cells promoted by lipoprotein (a). Science 1993;260:1555-8.

53 Hobbs HH, White AL. Lipoprotein(a): intrigues and insights. Curr Opin Lipidol 1999;10:225-36.

54 Kronenberg F, Steinmetz A, Kostner GM, et al. Lipoprotein(a) in health and disease. Crit Rev Clin Lab Sci 1996;33:495-543.

55 Djurovic S, Berg K. Epidemiology of $\mathrm{Lp}$ (a) lipoprotein: its role in atherosclerotic/thrombotic disease. Clin Genet 1997; 52:291-2.

56 Stein JH, Rosennson RS. Lipoprotein Lp(a) excess and coronary heart disease. Arch Intern Med 1997;157:1170-6.

57 Islam S, Gutin B, Smith C, et al. Association of apolipoprotein(a) phenotypes in children with family history of premature coronary artery disease. Arterioscler Thromb 1994;14:1609-16.

58 Slunga L, Asplund K, Johnson O, et al. Lipoprotein (a) in randomly selected 25-64 year old population: the northern Sweden MONICA study. F Clin Epidemiol 1993;46:617-24

59 Heinrich J, Sandkamp M, Kokott R, et al. Relationship of ipoprotein (a) to variables of coagulation and fibrinolysis in a healthy population. Clin Chem 1991;37:1950-4.

60 Mikhailidis DP, Spyropoulos KA, Ganotakis ES, et al. Fibrinogen and lipoprotein (a): associations in a population attending a cardiovascular risk clinic and effect of treatment with ciprofibrate. Fibrinolysis 1996;10(suppl): 17 .

61 Meade TW, Vickers MV, Thompson SG, et al. Epidemiological characteristics of platelet aggregability. BMF 1985 ; 290:428-32.

62 Mikhailidis DP, Barradas MA, Maris A, et al. Fibrinogen mediated activation of platelet aggregation and thromboxane $\mathrm{A}_{2}$ release: implications in vascular disease. $\mathcal{f}$ Clin Pathol 1985;38:1166-7

63 Cremer P, Nagel D, Labrot B, et al. Lipoprotein(a) as predictor of myocardial infarction in comparison to fibrinogen, LDL cholesterol and other risk factors: results from the prospective Goettingen risk incidence and preva-
lence study (GRIPS). Eur 7 Clin Invest 1994;24:444-53.

64 Thompson SG, Kienast J, Pyke SD, et al. Haemostatic factors and the risk of myocardial infarction or sudden death in patients with angina pectoris. European concerted action on thrombosis and disabilities angina pectoris study group. $N$ Engl F Med 1995;332:635-41.

65 Cremer P, Nagel D, Seidel D, et al. Considerations about plasma fibrinogen concentration and the cardiovascular plasma fibrinogen concentration and the cardiovascular risk: combined evidence from the
ies. Am $\mathcal{F}$ Cardiol 1996;78:380-1.

66 Fukujim MM, Martinez TL, Pinto LE, et al. Fibrinogen as independent risk factor for ischemic stroke. Arq Neuropsiq uiatr 1997;55:737-40

67 Beamer NB, Coull BM, Clark WM, et al. Persistent inflammatory response in stroke survivors. Neurology 1998;50 1722-8.

68 Cortinovis A, Crippa A, Crippa M. Blood rheology and fibrinogenemia: two independent parameters in the assessment of cerebral vascular damage. Minerva Med 1995;86: 511-18.

69 D'Erasmo E, Acca M, Celi FS, et al. Plasma fibrinogen and platelet count in stroke. $\mathcal{F}$ Med 1993;24:185-91.

70 Spinler SA, Cziraky M. Lipoprotein (a): physiologic lipid-lowering therapy. Ann Pharmacother 1994;28:343-51.

71 Ganotakis ES, Mikhailidis DP. Bezafibrate: treating hyperlipidemias as well as other cardiovascular risk factors. Today's Therapeutic Trends 1996;13:231-49.

72 Koenig W. Recent progress in the clinical aspects of fibrinogen. Eur Heart $\mathcal{F}$ 1995;16(suppl A):54-9.

73 Mathur S, Barradas MA, Mikhailidis DP, et al. The effects of a slow release formulation of bezafibrate on lipids, glucose homeostasis, platelets and fibrinogen in type II diabetics: a pilot study. Diabetes Res 1990;14:133-8.

74 Genest J, Jr, Malinow MR. Homocyst(e)ine and coronary artery disease. Curr Opin Lipidol 1992;3:295-9.

75 Clarke R, Daly L, Robinson K, et al. Hyperhomocysteinemia: an independent risk factor for vascular disease. N Engl f Med 1991;324:1149-55.

76 Hopkins PN, Wu LL, Hunt SC, et al. Lipoprotein(a) interactions with lipid and nonlipid risk factors in early familia coronary artery disease. Arterioscler Thromb Vasc Biol 1997; 17:2783-92.

77 Durand P, Lussier-Cacan S, Blache D. Acute methionine load-induced hyperhomocysteinemia enhances platelet aggregation, thromboxane biosynthesis, and macrophagederived tissue factor activity in rats. FASEB $₹$ 1997; 11: 1157-68.

78 Nishio E, Watanabe Y. Homocysteine as a modulator of platelet-derived growth factor action in vascular smooth
muscle cells: a possible role for hydrogen peroxide. $\mathrm{Br} \mathcal{7}$ Phuscle cells: a possible role
79 Khachigian LM, Chesterman CN. Platelet-derived growth factor and its receptor: structure and roles in normal factor and its receptor: structure and roles
growth and pathology. Platelets 1993;4:304-15.

80 Sacco RL, Roberts JK, Jacobs BS. Homocysteine as a risk factor for ischemic stroke: an epidemiological story in evolution. Neuroepidemiology 1998;17:167-73.

81 Vila N, Deulofeu R, Chamorro A, et al. Plasma homocysteine levels in patients with ischemic cerebral infarction. Med Clin (Barc) 1998;110:605-8.

82 Harpel PC, Chang VT, Borth W. Homocysteine and other sulfydryl compounds enhance the binding of lipoprotein (a) to fibrin: a potential link between thrombosis, atherogenesis, and sulfydryl compound metabolism. Proc Natl Acad Sci U S A 1992;89:10193-7.

83 Bartens W, Rader DJ, Talley G, et al. Lipoprotein (a) in patients with hyperlipidaemia. Eur $\mathcal{F}$ Clin Invest 1995;25: $647-53$

84 Wild SH, Fortmann SP, Marcovina SM. A prospective casecontrol study of lipoprotein(a) levels and apo(a) size and risk of coronary heart disease in Stanford five-city project
participants. Arterioscler Thromb Vasc Biol 1997;17:239-45.

5 Kronenberg F, Steinmetz A, Kostner GM, et al. Lipoproein(a) in health and disease. Crit Rev Clin $\mathrm{Lab} \mathrm{Sci}$ 1996;33:495-543.

86 Catalano M, Perilli E, Carsaniga G, et al. Lp(a) in hypertensive patients. F Hum Hypertens 1998;12:83-9.

87 Gazzaruso C, Buscaglia P, Garzaniti A, et al. Association of lipoprotein (a) levels and apolipoprotein(a) phenotypes with coronary heart disease in patients with essential with coronary heart disease in patients

88 Freeman DJ, Griffin BA, Murray E, et al. Smoking and plasma lipoproteins in man: effects on low density lipoprotein cholesterol levels and high density lipoprotein s

89 Pandolfi C, Pellegrini L, Dede A, et al. Lipoprotein (a), parameters of lipid metabolism and hemostasis in obese patients. Minerva Endocrinol 1997;22:13-17.

90 Boman L, Ericson M. Lipoprotein (a) levels after intestinal bypass operation for morbid obesity. Obesity Surgery 1997; 7:125-7.

91 Zamboni M, Facchinetti R, Armellini F, et al. Effects of visceral fat and weight loss on lipoprotein (a) concentration in subjects with obesity. Obes Res 1997;5:332-7.

92 Rastenyte D, Tuomilehto J, Domarkiene S, et al. Risk factors for death from stroke in middle-aged Lithuanian men: results from a 20-year prospective study. Stroke 1996;27: 672-6.

93 Palmer A, Bulpitt C, Beevers G, et al. Risk factors for ischaemic heart disease and stroke mortality in young and old hypertensive patients. F Hum Hypertens 1995;9:695-7.

94 Menotti A, Blackburn H, Kromhout D, et al. The inverse relation of average population blood pressure and stroke mortality rates in the seven countries study: a paradox. Eur F Epidemiol 1997;13:379-86.

95 Prospective Studies Collaboration Group. Cholesterol, diastolic blood pressure, and stroke: 13,000 strokes in 450,000 people in 45 prospective cohorts. Lancet 1995; 346:1647-53.

96 Emond MJ, Zareba W. Prognostic value of cholesterol in women of different ages. Fournal of Women's Health 1997;6: 295-307.

97 Korn-Lubetzki I, Kleinman Y, Eliashiv S, et al. Correlation between serum lipids and stroke in an Israeli population. Neurol Res 1992;14(suppl 2):78-80.

98 Ozawa H, Aono H, Saito I, et al. Atherosclerosis and clinical examination: epidemiology of stroke and ischemic heart disease. Rinsho Byori-Japan. F Clin Pathol 1996;44:101526.

99 Puddey IB. Low serum cholesterol and the risk of cerebral haemorrhage. Atherosclerosis 1996;119:1-6.

100 Iribarren C, Jacobs DR, Sadler M, et al. Low total serum cholesterol and intracerebral hemorrhagic stroke: is the association confined to elderly men? The Kaiser permaassociation confined to elderly men? The Kaiser perm
nente medical care program. Stroke 1996;27:1993-8.

101 Gatchev O, Rastam L, Lindberg G, et al. Subarachnoid haemorrhage, cerebral haemorrhage and serum cholesterol concentration in men and women. Ann Epidemiol 1993;3: 403-9

102 Iso H, Jacobs DR, Jr, Wentworth D, et al. Serum cholesterol levels and six-year mortality from stroke in 350,977 men screened for the multiple risk factor intervention trial. N Engl f Med 1989;320:904-10.

103 Neaton JD, Blackburn H, Jacobs D, et al. Serum cholesterol level and mortality findings for men screened in the multiple risk factor intervention trial. Multiple risk factor intervention trial research group. Arch Intern Med 1992; 152:1490-500.

104 Palomaki H, Kaste M, Raininko R, et al. Risk factors for cervical atherosclerosis in patients with transient ischaemic attack or minor ischaemic stroke. Stroke 1993;24:970-5.

105 Fonte G, Bo M, Poli L, et al. Ischemic stroke and transient ischaemic attacks: a case-control study of the risk factors in elderly hospitalized patients. Recenti Prog Med 1993;84: 254-62

106 Jacobs DR. The relationship between cholesterol and stroke. Health Rep 1994;6:87-93.

107 Di Mascio R, Marchioli R, Vitullo F, et al. Serum cholesterol and risk of ischaemic stroke: results of a case-control study. On behalf of PROGETTO 3A investigators. Prev Med 1995;24:128-33.

108 Ryu JE, Howard G, Craven TE, et al. Postprandial triglyceridemia and carotid atherosclerosis in middle-aged subjects. Stroke 1992;23:823-8. 
109 Lindenstrom E, Boysen G, Nyboe J. Influence of total cholesterol, high-density lipoprotein cholesterol, and trig-
lycerides on risk of cerebrovascular disease: the Copenhalycerides on risk of cerebrovascular disease:
gen city heart study. BMF 1994;309:11-15.

110 Gordon T, Kannel WB, Castelli WP, et al. Lipoproteins, cardiovascular disease and death: the Framingham study. Arch Intern Med 1981;141:1128-31.

111 Pedro-Bodet J, Senti M, Nogues X, et al. Lipoprotein and apoprotein profile in men with ischemic stroke: role of lipoprotein (a), triglyceride-rich lipoproteins and apolipoprotein E polymorphism. Stroke 1992;23:1557-662.

112 Coudec R, Mahieux F, Bailleul S, et al. Prevalence of apolipoprotein $\mathrm{E}$ phenotypes in ischemic cerebrovascular disease. A case-control study. Stroke 1993;24:661-4.

113 World Health Organisation. Tobacco or health: a global status report. Geneva: World Health Organisation, 1997.

114 Reed DM. The paradox of high risk of stroke in population with low risk of coronary heart disease. Am $\mathcal{f}$ Epidemiol with low risk of 1 1990;131:579-88.

115 Jurgens G, Koltringer P. Lipoprotein (a) in ischemic cerebrovascular disease: a new approach to the assessment cerebrovascular disease: a new approach to the
of risk for stroke. Neurology 1987;37:513-15.

116 Lindgren A, Nilsson-Ehle P, Norrving B, et al. Plasma lipids and lipoproteins in subtypes of stroke. Acta Neurol Scand 1992;86:572-8.

117 Vavernova H, Novotny D, Ficker L, et al. Lipoprotein (a): a genetic risk factor for early ischemic cerebrovascular stroke. Vnitr Lek 1993;39:979-87.

118 Jurgens G, Taddei-Peters WC, Koltringer P, et al. Lipoprotein (a) serum concentration and apolipoprotein (a) phenotype correlate with severity and presence of ischemic cerebrovascular disease. Stroke 1995;26:1841-8.

119 Peynet J, Beaudeux JL, Woimant F, et al. Apolipoprotein (a) size polymorphism in young adults with ischemic stroke. Atherosclerosis 1999;142:233-9.

120 Van Kooten F, van Krimpen J, Dippel DW, et al. Lipoprotein (a) in patients with acute cerebral ischemia. Stroke tein (a) in patients

121 Margaglione M, DiMinno G, Grandone E, et al. Plasma lipoprotein (a) in subjects attending a metabolic ward. Dislipoprotein (a) in subjects attending a metabolic ward. Dishistory of ischemic stroke. Arterioscl Thromb Vasc Biol 1996; history of isch

122 Nagayama M, Shinohara Y, Nagayama T. Lipoprotein (a) and ischemic cerebrovascular disease in young adults. Stroke 1994;25:74-8

123 Peng D-Q, Zhao SP, Wang JL. Lipoprotein (a) and apolipoprotein $\mathrm{E}$ e4 as independent risk factors in ischemic stroke. $\mathcal{F}$ Cardiovasc Risk 1999;6:1-6.

124 National Institute of Neurological Disorders and Stroke Ad Hoc Committee (Whisnant JP, Basford JR, Bernstein $\mathrm{EF}$, et al). Classification of cerebrovascular disorders III. Stroke 1990;21:637-76.

125 Kawamoto, A, Shimada K, Matsubayashi K, et al. Factors associated with silent multiple lacunar lesions on magnetic resonance imaging in asymptomatic elderly hypertensive patients. Clin Exp Pharmacol Physiol 1991;18:605-10.

126 Kario K, Matsuo T, Kobayashi H, et al. "Silent" cerebral infarction is associated with hypercoagulability, endothelial infarction is associated with hypercoagulability, endothelial cell damage, and high Lp(a) levels in elderly
rioscler Thromb Vasc Biol 1996;16:734-41.

127 Schreiner PJ, Chambless LE, Brown SA, et al. Lipoprotein (a) as a correlate of stroke and transient ischemic attack prevalence in a biracial cohort: the ARIC study. Atherosclerosis risk in communities. Ann Epidemiol 1994;4:351-9.

128 Ichinose A, Suzuki K, Saito T. Apolipoprotein (a) and thrombosis: molecular and genetic bases of hyperlipoprotein (a)-emia. Semin Thromb Hemost 1998;24:23743.

129 Hachinski V, Graffagnino C, Beaudry M, et al. Lipids and stroke: a paradox resolved. Arch Neurol 1996;53:303-8.

130 Glader CA, Stegmayr B, Boman J, et al. Chlamydia pneumoniae antibodies and high lipoprotein(a) levels do not predict ischemic cerebral infarctions: results from a nested case-control study in northern Sweden. Stroke 1999;30: 2013-18.

131 Alfthan G, Pekkanen J, Jauhianen M, et al. Relation of serum homocysteine and lipoprotein (a) concentrations to serum homocysteine and lipoprotein (a) concentrations to atherosclerotic disease in a prospective Fin

132 Ridker PM, Stampfer MJ, Hennekens CH. Plasma concentration of lipoprotein (a) and the risk of future stroke. FAMA 1995;273:1269-73.

133 Wissler RW, Vesslinovitch D. Atherosclerosis in nonhuman primates. Adv Vet Sci Comp Med 1977;21:351-420
134 Weber G, Fabbrini P, Resi L, et al. An ultrastructural comparison of diet-induced atherosclerosis of arteries supply-
ing the central nervous system in cynomolgus and rhesus monkeys. Appl Pathol 1983;1:121-38.

135 Weber G, Alessandrini C, Centi L, et al. Delayed development of intimal lesions in cerebral arteries of spontaneous hypertensive rats subjected to a short term atherogenic diet (TEM observations). Appl Pathol 1986;4:233-7.

136 Postiglione A, Napoli C. Hyperlipidemia and atherosclerotic cerebrovascular disease. Curr Opin Lipidol 1995;6: 236-42.

137 Postiglione A, Rubba P, de Simone B, et al. Carotid atherosclerosis in familial hypercholesterolemia. Stroke 1985;16: 658-61.

138 Landray MJ, Sagar G, Muskin J, et al. Association of atherogenic low-density lipoprotein subfractions with atherogenic low-density lipoprotein subfraction

139 Williams JK, Bellinger DA, Nichols TC, et al. Occlusive arterial thrombosis in cynomolgus monkeys with varying plasma concentrations of lipoprotein (a). Arterioscler Thromb 1993; 13:548-54.

140 Jurgens G, Koltringer P. Cerebrovascular disease and $\mathrm{Lp}$ (a): its role in atherosclerotic plaque formation and vessel wall elasticity of the carotid arteries. Chem Phys Lipids 1994;67-68:429-34.

141 Watts GF, Mazurkiewicz JC, Tonge K, et al. Lipoprotein (a) as a determinant of the severity of angiographically
defined carotid atherosclerosis. Qf Med 1995;88:321-6.

142 Cohen A, Tzourio C, Bertrand B, et al. Aortic plaque morphology and vascular events: a follow-up study in patients with ischemic stroke. FAPS investigators. French study of aortic plaques in stroke. Circulation 1997;96:3838-41.

143 Heinzlef O, Cohen A, Amarenco P. An update on aortic causes of ischemic stroke. Curr Opin Neurol 1997;10:6472 .

144 Delanty N, Vaughan C. Vascular effects of statins in stroke. Stroke 1997;28:2315-20.

145 Hornstra G, Houwelingen AC, Kester ADM, et al. A palm oil-enriched diet lowers serum $\mathrm{Lp}(\mathrm{a})$ in normocholesterolemic volunteers. Atherosclerosis 1991;90:91-3.

146 Berg-Schmith E, Klausen IC, Kristensen SD, et al. The effect of n-3 polyunsaturated fatty acids on $\mathrm{Lp}(\mathrm{a})$. Clin Chim Acta 1991;198:271-8.

147 Sacks FM, Pfeffer MA, Moye LA, et al for the Cholesterol and Recurrent Events Trial Investigators. The effect of pravastatin on coronary events after myocardial infarction in patients with average cholesterol levels. $N$ Engl $\mathrm{F} \mathrm{Med}$ 1996;335:1001-9.

148 The Long-term Intervention with Pravastatin in Ischemic Disease (LIPID) Study Group. Prevention of cardiovascular events and death with pravastatin in patients with coronary heart disease and a broad range of initial cholesterol levels. N Engl f Med 1998;339:1349-57.

149 Behar S for the BIP Study Group. Lowering fibrinogen levels: clinical update. Blood Coagul Fibrinolysis 1999; 10 (suppl 1):S41-3.

150 Rubins HB, Robins SJ, Collins D, et al. Gemfibrozil for the secondary prevention of coronary heart disease in men with low levels of high-density lipoprotein cholesterol. Veterans affairs high-density lipoprotein cholesterol intervention trial study group. N Engl f Med 1999;341:410-18.

151 Kostner GM, Krempler F. Lipoprotein (a). Curr Opin Lipidol 1992;3:279-84.

152 Elkeles RS, Diamond JR, Poulter C, et al. Cardiovascular outcomes in type 2 diabetes. A double-blind placebocontrolled study of bezafibrate: the St Mary's, Ealing, Northwick Park diabetes cardiovascular disease prevention (SENDCAP) study. Diabetes Care 1998;21:641-8.

153 Papadakis JA, Ganotakis ES, Jagroop IA, et al. Effect of hypertension and its treatment on lipid, lipoprotein (a), fibrinogen, and bilirubin levels in patients referred for dyslipidemia. Am F Hypertens 1999;12:673-81.

154 Taskinen MR, Puolakka J, Pyorala T, et al. Hormone replacement therapy lowers plasma $\mathrm{Lp}$ (a) concentrations. Comparison of cyclic transdermal and continuous estrogen-progestin regimens. Arterioscler Thromb Vasc Biol 1996;16:1215-21.

155 van der Mooren MJ, Mijatovic V, van Baal WM, et al. Hormone replacement therapy in postmenopausal women with pecific risk factors for coronary artery disease. Maturitas 1998;30:27-36.

156 Maher V, Marcovina S, Hilga L, et al. Effects of lowering elevated low-density lipoprotein cholesterol on the cardiovascular risk of lipoprotein (a). $\mathcal{F A M A ~ 1 9 9 5 ; 2 7 4 : 1 7 7 1 - 4 . ~}$ 